\title{
Karakteristik Gangguan Dengar Sensorineural Kongenital pada Anak yang Dideteksi dengan Brainstem Evoked Response Audiometry
}

\author{
Yussy Afriani Dewi, Ratna Anggraeni Agustian \\ Departemen Ilmu Kesehatan Telinga, Hidung, Tenggorok, Bedah Kepala dan Leher \\ Fakultas Kedokteran Universitas Padjadjaran-Rumah Sakit Dr. Hasan Sadikin, Bandung
}

\begin{abstract}
Abstrak
Gangguan dengar merupakan salah satu kelainan yang sering timbul sejak lahir (kongenital), sehingga deteksi dan rehabilitasi dini yang tepat dapat meningkatkan perkembangan bicara dan berbahasa. Penelitian ini dilakukan untuk mengetahui berbagai aspek gangguan dengar kongenital dari segi klinik maupun sosiologik. Subjek penelitian adalah anak yang dilakukan brainstem evoked response audiometry (BERA) di Rumah Sakit Dr. Hasan Sadikin dengan gangguan dengar sensorineural bilateral kongenital selama periode April 2002-April 2005. Penelitian dilakukan secara deskriptif retrospektif. Sebanyak 286 anak termasuk dalam penelitian terdiri atas $149(52,1 \%)$ laki-laki dan 137 (47,9\%) perempuan. Sebanyak 58,7\% terdeteksi pada usia $>1-3$ tahun. Usia anak saat dicurigai menderita gangguan dengar mulai dari usia 5 bulan sampai 14 tahun. Tenggang waktu antara usia pada saat mulai dicurigai adanya gangguan dengar dan dilakukan BERA adalah $82(28,7 \%) \leq 6$ bulan, $72(25,2 \%)$ antara $>6$ bulan sampai $\leq 1$ tahun, dan $70(24,4 \%)$ antara $>1$ sampai $\leq 2$ tahun. Penderita lebih banyak berasal dari daerah perkotaan, yaitu $149(52,1 \%)$ anak dan sebagian besar dirujuk oleh spesialis THT sebanyak $129(45,1 \%)$. Derajat gangguan dengar terbanyak adalah berat $181(63,3 \%)$ dan sangat berat $96(33,6 \%)$, sebagian besar bersifat simetris $(71 \%)$. Faktor risiko terbanyak tidak teridentifikasi $(51,1 \%)$, prematur/BBLR $(13,6 \%)$, asfiksia $(13,3 \%)$, hiperbilirubinemia $(8,7 \%)$, dan rubela $(7,3 \%)$. Simpulan, usia curiga pada saat anak dideteksi mengalami gangguan dengar masih tinggi. Agar deteksi dapat lebih dini, perlu peningkatan pengetahuan tenaga kesehatan dan masyarakat serta upaya pencegahan terhadap faktor risiko. [MKB. 2011;43(2):77-82].
\end{abstract}

Kata kunci: Anak, brainstem evoked response audiometry (BERA), gangguan dengar sensorineural bilateral kongenital

\section{Characteristic of Congenital Bilateral Sensorineural Hearing Loss in Children Diagnosed by Brain Evoked Response Audiometry}

\begin{abstract}
Hearing loss is one of the most common congenital anomalies, therefore early detection and rehabilitation might enhance speech ability. The purpose of this study was to explore the clinical and sociological characteristics of congenital bilateral sensorineural hearing loss. Subjects were children who suffered from congenital bilateral sensorineural hearing loss diagnosed by brainstem evoked response audiometry (BERA) in Dr. Hasan Sadikin Hospital from period of April 2002-April 2005. Data obtained retrospectively from patient's record and presented descriptively. There were 286 children included in the study consisted of 149 (52.1\%) males and $137(47.9 \%)$ females. More $(58.8 \%)$ children were detected by BERA at age of $>1-3$ years. Children's age that first suspected to have hearing disorder was between 5 months and 14 years old. The delay between suspected and diagnosis was $82(28.7 \%) \leq 6$ months, $72(25.2 \%)$ between $>6$ months $-\leq 1$ year, $70(24.4 \%)$ between $>1-\leq 2$ years. There were $52.1 \%$ (149) subjects came from urban area and $45.1 \%$ (129) of them were referred by otolaryngology-head and neck surgery specialists. The degrees of hearing loss were severe $181(63,3 \%)$ and profound $96(33.6 \%)$. Most cases $(71 \%)$ were symmetrical. The cause of hearing loss in $51.1 \%$ of children couldn't be determined, $13.6 \%$ were premature/low birth weight, $13.6 \%$ asphyxia, $8.7 \%$ hyperbilirubinemia, and $7.3 \%$ rubella. Conclusions, age of children when suspected to have hearing disorder is still high. Early detection needs knowledge from health provider officer, society, and prevention of the risk factors. [MKB. 2011;43(2):77-82].
\end{abstract}

Key words: Brainstem evoked response audiometry (BERA), child, congenital bilateral sensorineural hearing loss

Korespondensi: Yussy Afriani Dewi, dr., M.Kes., SpTHT-KL, Departemen Ilmu Kesehatan Telinga, Hidung, Tenggorok, Bedah Kepala, dan Leher Fakultas Kedokteran Universitas Padjadajaran-Rumah Sakit Dr. Hasan Sadikin Bandung, jalan Kamper Kencana no. 9-12 Kamper Cluster Bumi Panyawangan Cileunyi Bandung, telepon (022) 87825554, mobile08112272773,e-mail: yussyad@yahoo.com 


\section{Pendahuluan}

Gangguan dengar secara garis besar dapat disebabkan oleh faktor genetik (bawaan) dan faktor nongenetik (didapat). Gangguan dengar juga dapat timbul sejak lahir (prelingual) atau timbul setelah usia tiga tahun (postlingual) yang akan mempengaruhi kemampuan komunikasi penderita.

Gangguan dengar pada anak merupakan salah satu kelainan yang sering timbul sejak lahir (kongenital), umumnya tipe sensorineural, bersifat bilateral, sebagian besar derajat berat dan sangat berat. Tahun pertama sampai tahun ketiga kehidupan merupakan masa yang sangat penting bagi anak untuk belajar mendengar dan mengembangkan kemampuan berbicara serta berbahasa. ${ }^{1}$ Bila gangguan dengar bilateral terjadi sejak lahir atau sebelum periode perkembangan bicara (prelingual) akan mengganggu perkembangan bicara, berbahasa, dan kognitif. Deteksi dan rehabilitasi dini yang tepat akan memberikan peluang yang sangat besar untuk perkembangan bicara dan berbahasa yang lebih baik..$^{2-4}$

Angka kejadian gangguan dengar sensorineural bilateral kongenital adalah 1-3/1.000 kelahiran pada populasi perawatan bayi normal dan 2-4/100 bayi di perawatan intensif. Di Jawa Barat dengan penduduk sekitar 37 juta jiwa dan angka pertambahan penduduk sebesar $1,8 \%$ per tahun, diperkirakan sedikitnya 600 bayi lahir dengan gangguan dengar sensorineural bilateral berat. ${ }^{5}$

Di negara berkembang deteksi dini gangguan dengar belum berjalan dengan sempurna, masih banyak didapatkan masalah dengar pada anak setelah mencapai usia dua tahun bahkan lebih, pada usia yang seharusnya anak sudah mampu berbicara. Hal ini disebabkan kurangnya pemahaman orangtua mengenai pentingnya fungsi dengar sebagai dasar proses perkembangan bicara. ${ }^{6}$

Joint Committee on Infant Hearing (JCIH) 2000 menetapkan gangguan dengar pada anak sebaiknya sudah dapat dideteksi pada usia 3 bulan dan intervensi yang tepat dimulai pada usia 6 bulan. Intervensi tersebut dengan amplifikasi melalui pemasangan alat bantu mendengar (ABM), implantasi koklea, dan pendidikan khusus (terapi wicara, SLB-B) sebagai upaya rehabilitasi, sehingga diharapkan anak dapat mencapai kemampuan berbicara dan berbahasa yang optimal. ${ }^{3}$

Anak dengan gangguan dengar yang didiagnosis secara dini (sebelum usia 6 bulan) dan dilakukan intervensi pada usia 6 bulan akan mencapai perkembangan berbahasa jauh lebih baik daripada bila dilakukan intervensi pada usia $>6$ bulan. Anak dengan gangguan dengar dan kognitifnya normal, bila dilakukan intervensi sebelum atau pada usia 6 bulan akan mempunyai kemampuan perkembangan berbahasa normal. Anak dengan gangguan dengar yang diintervensi $>6$ bulan, tetapi $<36$ bulan mencapai perkembangan berbahasa yang hampir sama. Anak dengan gangguan dengar yang mendapat pendidikan dan penatalaksanaan gangguan dengar pada tahun pertama kehidupannya, memiliki peluang $>50 \%$ untuk dapat mengikuti pendidikan secara integrasi di sekolah umum di kemudian hari. ${ }^{7,8}$

Deteksi dini sangat penting, terutama harus dilakukan pada anak dengan faktor risiko gangguan dengar, karena $50 \%$ bayi baru lahir dengan faktor risiko mengalami gangguan dengar sejak lahir. Deteksi gangguan dengar pada anak dapat dilakukan dengan pemeriksaan audiologi subjektif, yaitu dengan memperhatikan respons anak terhadap bunyi berupa perubahan tingkah laku atau dengan pemeriksaan objektif, misalnya brainstem evoked response audiometry (BERA) dan oto-acoustic emmision (OAE). Kelebihan pemeriksaan BERA adalah objektif dan reliabel sehingga sangat bermanfaat pada penderita yang tidak kooperatif, bayi, dan anak. Dengan alat ini dapat ditentukan ambang dengar secara objektif serta tipe gangguan dengarnya. Alat ini mempunyai sensitivitas $98 \%$ dan spesifisitas 96\%. Pemeriksaan OAE ideal untuk menilai integritas sel rambut luar di dalam koklea dan skrining, karena dapat memeriksa bayi mulai usia satu hari dalam waktu beberapa menit saja, tetapi tidak dapat menunjukkan ambang dengar, hanya memperkirakan apakah anak mendengar atau tidak, sehingga perlu diperiksa lebih lanjut dengan pemeriksaan lain seperti BERAdan audiometri. , $9-12^{-12}$

Tujuan penelitian ini adalah untuk mengetahui berbagai aspek gangguan dengar kongenital dari segi klinik maupun sosiologik.

\section{Metode}

Subjek penelitian adalah anak yang terdeteksi menderita gangguan pendengaran sensorineural bilateral yang timbul sejak lahir (kongenital) berdasarkan hasil pemeriksaan BERA di Subbagian Audiologi Ilmu Kesehatan THT-KL Fakultas Kedokteran Universitas Padjadjaran-Rumah Sakit Hasan Sadikin Bandung periode April 2002-April 2005.

Penelitian ini adalah deskriptif-retrospektif yang diambil dari data rekam medis. Semua anak yang mengalami gangguan dengar tipe sensorineural pada kedua telinga (bilateral) dan timbul sejak lahir (kongenital) dilakukan pemeriksaan BERA. Semua data yang terkumpul dalam catatan medis hasil pemeriksaan BERA dibahas dan disusun ke dalam tabel dan grafik berdasarkan angka kejadian gangguan pendengaran, lamanya tenggang waktu antara usia curiga dan usia periksa, sumber rujukan, jenis, derajat, sifat gangguan pendengaran, dan 
kemungkinan faktor risiko. Data diolah dengan menggunakan program komputer SPSS-PC versi 12.0 for windows 98 .

\section{Hasil}

Selama tiga tahun penelitian terdapat 624 anak yang diperiksa BERA umumnya karena orangtua mencurigai adanya gangguan dengar dan terlambat berbicara. Dari sejumlah anak tersebut terdapat $270(43,3 \%)$ anak dengan pendengaran normal dan $354(56,7 \%)$ anak dengan gangguan dengar. Dari 354 anak tersebut, terdapat $68(19,2 \%)$ anak dengan gangguan dengar yang tidak termasuk subjek penelitian, yaitu $24(6,8 \%)$ anak dengan gangguan dengar didapat (bukan kongenital), 17 $(4,8 \%)$ anak dengan gangguan dengar konduktif kongenital, dan 27 anak $(9,4 \%)$ dengan gangguan dengar unilateral kongenital. Subjek penelitian adalah jumlah anak dengan gangguan dengar kongenital bilateral sebanyak $286(45,8 \%)$ anak.

Terdapat 286 sensorineural hearing loss (SNHL) bilateral kongenital dengan $168(58,7 \%)$ anak berusia $>1-3$ tahun, $65(22,7 \%)$ anak usia antara $>3$ tahun sampai $>5$ tahun, $37(12,9 \%)$ anak berusia $\geq 5$ tahun. Anak kelompok usia sangat dini dan usia dini hanya sebagian kecil, yaitu 3 $(1,1 \%)$ anak usia $0-6$ dan $13(4,6 \%)$ anak usia $>6$ bulan-1 tahun. Laki-laki sedikit lebih tinggi

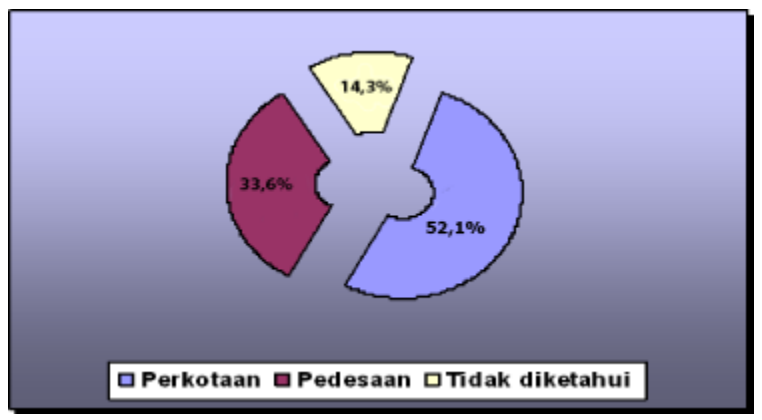

Gambar 1 Jumlah Subjek Penelitian berdasarkan Daerah Asal

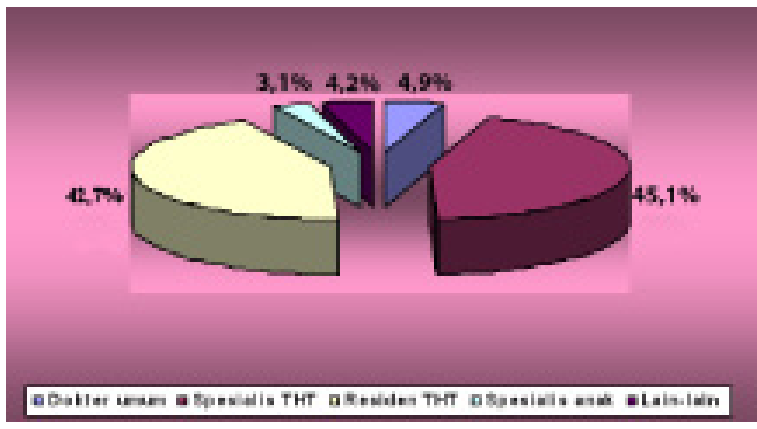

\section{Gambar 2 Jumlah Rujukan berdasarkan Sumber Rujukan}

daripada perempuan, yaitu 149 (52,1\%) dan 137 $(47,9 \%)$.

Didapatkan kesenjangan antara usia curiga dan usia saat diperiksa BERA. Sebagian besar lama kesenjangan tersebut pada $82 \quad(28,7 \%)$ anak adalah $\leq 6$ bulan, $72(25,2 \%)$ anak $>6$ bulan sampai $\leq 1$ tahun, $70(24,5 \%)$ anak $>1$ tahun sampai $\leq 2$ tahun, $33(11,5 \%)>3$ tahun, dan 29 $(10,1 \%)$ anak antara $>2$ tahun sampai $\leq 3$ tahun.

Gambar 1 memperlihatkan $149 \quad(52,1 \%)$ subjek penelitian berasal dari daerah perkotaan, $96(33,6 \%)$ berasal dari daerah pedesaan, dan 41 $(14,3 \%)$ tidak diketahui daerah asalnya karena alamatnya tidak jelas.

Didapatkan jumlah perujuk terbanyak adalah dokter spesialis THT sebanyak $129(45,1 \%)$ orang dan residen THT 122 (42,7\%) orang. Terdapat 14 $(4,9 \%)$ orang yang dirujuk oleh dokter umum, 9 $(3,1 \%)$ orang oleh dokter spesialis anak, dan 12 $(4,2 \%)$ orang perujuknya tidak tercatat atau tidak jelas.

Tabel 1 memperlihatkan bahwa semua kelompok usia angka kejadian gangguan pendengaran sebagian besar adalah derajat berat $181(63,3 \%)$ dan sangat berat $96(33,6 \%)$ anak.

Gangguan pendengaran simetris lebih banyak dibandingkan dengan gangguan pendengaran asimetris untuk semua derajat gangguan pendengaran.

Terdapat perbedaan derajat gangguan pendengaran antara laki-laki dan perempuan. Pada

Tabel 1 Derajat Gangguan Dengar berdasarkan Kelompok Usia

\begin{tabular}{|c|c|c|c|c|c|c|c|c|c|c|}
\hline \multirow{2}{*}{ Usia } & \multicolumn{2}{|c|}{ Ringan } & \multicolumn{2}{|c|}{ Sedang } & \multicolumn{2}{|c|}{ Berat } & \multicolumn{2}{|c|}{ Sangat Berat } & \multicolumn{2}{|c|}{ Jumlah } \\
\hline & 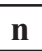 & $\%$ & n & $\%$ & $n$ & $\%$ & n & $\%$ & $n$ & $\%$ \\
\hline$\leq 6$ bulan & - & - & - & - & 3 & 1,1 & - & - & 3 & 1,1 \\
\hline$>6$ bln- 1 thn & 1 & 0,35 & 1 & 0,35 & 8 & 2,8 & 3 & 1,1 & 13 & 4,6 \\
\hline$>1-3$ tahun & 2 & 0,7 & 5 & 1,7 & 108 & 37,8 & 53 & 18,5 & 168 & 58,7 \\
\hline$>3-5$ tahun & - & - & - & - & 38 & 13,3 & 27 & 9,4 & 65 & 22,7 \\
\hline$\geq 5$ tahun & - & - & - & - & 24 & 8,4 & 13 & 4,5 & 37 & 12,9 \\
\hline Jumlah & 3 & 1,0 & 6 & 2,1 & 181 & 63,3 & 96 & 33,6 & 286 & 100 \\
\hline
\end{tabular}




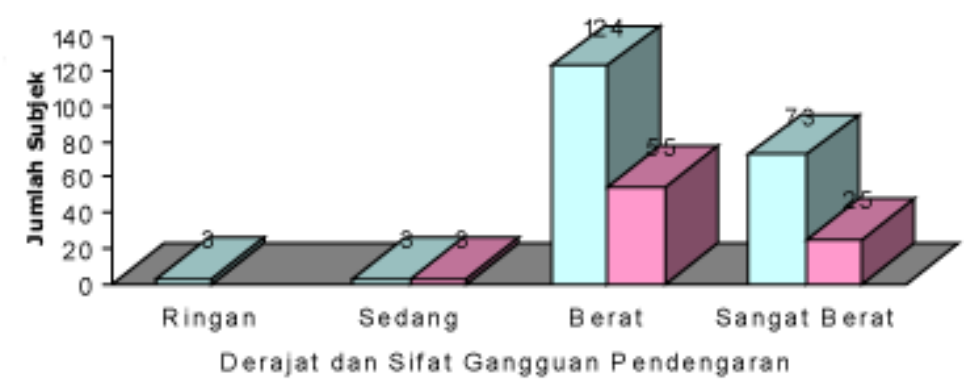

Gambar 3 Derajat dan Sifat Gangguan Dengar

derajat berat perempuan (92 orang) sedikit lebih banyak daripada laki-laki (89 orang), pada derajat sangat berat laki-laki (55 orang) lebih tinggi dari perempuan (41 orang), sedangkan pada derajat ringan dan sedang hampir sama.

Faktor risiko terbanyak adalah tidak dapat diidentifikasi $(51,1 \%)$, prematur $(13,6 \%)$, asfiksia $(13,3 \%)$, hiperbilirubinemia $(8,7 \%)$, serta rubela $(7,4 \%)$. Sebagian besar faktor risiko menimbulkan gangguan dengar derajat berat dan sangat berat dengan perbandingan yang bervariasi.

\section{Pembahasan}

Gangguan dengar sebagian timbul sejak lahir (kongenital) yang bersifat bilateral sebanyak 286 anak, sedangkan gangguan dengardidapat sebanyak 24 anak. Hal ini sesuai dengan kepustakaan bahwa gangguan dengar pada anak sering kongenital dan umumnya bersifat sensorineural bilateral. ${ }^{2}$

Bila mengacu pada standar JCIH, usia diagnosis yang didapatkan pada penelitian ini belum mencapai standar optimal karena gangguan dengar kongenital pada anak harus sudah terdeteksi pada usia $\leq 3$ bulan dan dilakukan rehabilitasi mulai usia 6 bulan. Keterlambatan diagnosis akan mengganggu perkembangan bicara, berbahasa, dan kognitif anak tersebut. Bila dilakukan rehabilitasi kelompok usia $<6$ bulan, maka akan tercapai perkembangan bicara dan berbahasa yang paling optimal, pada kelompok usia 6 bulan-3 tahun mempunyai prognosis yang hampir sama, tetapi kurang optimal dan kelompok usia $>3$ tahun mempunyai prognosis yang kurang baik. ${ }^{4,13}$

Pada penelitian ini didapatkan kejadian gangguan dengar pada laki-laki sedikit lebih tinggi daripada perempuan. Hal ini sesuai dengan sebagian besar negara Eropa bahwa kejadian gangguan dengar lebih banyak ditemukan pada laki-laki dibandingkan dengan perempuan. Selain itu didapatkan kesenjangan antara usia curiga dan usia saat diperiksa BERA yang sesuai dengan kepustakaan, bahwa di negara berkembang masih

Tabel 2 Faktor Risiko berdasarkan Derajat Gangguan Dengar

\begin{tabular}{ccccccccccc}
\hline \multirow{2}{*}{$\begin{array}{c}\text { Kemungkinan } \\
\text { Faktor Risiko }\end{array}$} & \multicolumn{2}{c}{ Ringan } & \multicolumn{2}{c}{ Sedang } & \multicolumn{3}{c}{ Berat } & \multicolumn{2}{c}{ Sangat Berat } & \multicolumn{2}{c}{ Jumlah } \\
\cline { 2 - 10 } & $\mathbf{n}$ & $\mathbf{\%}$ & $\mathbf{n}$ & $\mathbf{\%}$ & $\mathbf{n}$ & $\mathbf{\%}$ & $\mathbf{n}$ & $\mathbf{\%}$ & $\mathbf{n}$ & $\mathbf{\%}$ \\
\hline Herediter & - & - & - & - & 10 & 3,5 & 4 & 1,4 & 14 & 4,9 \\
Rubela & - & - & - & - & 18 & 6,3 & 3 & 1,1 & 21 & 7,4 \\
Ototoksik prenatal & - & - & - & - & 2 & 0,7 & 1 & 0,3 & 3 & 1,0 \\
Hiperbilirubinemia & - & - & - & - & 19 & 6,6 & 6 & 2,1 & 25 & 8,7 \\
Prematur/BBLR & - & - & 1 & 0,3 & 28 & 9,8 & 10 & 3,5 & 39 & 13,6 \\
Asfiksia & - & - & - & - & 23 & 8,0 & 15 & 5,3 & 38 & 13,3 \\
Tidak dapat & 3 & 1,1 & 5 & 1,8 & 81 & 28,3 & 57 & 19,9 & 146 & 51,1 \\
\hline diidentifikasi & 3 & & & & & & & \\
Jumlah & $\mathbf{3}$ & $\mathbf{1 , 1}$ & $\mathbf{6}$ & $\mathbf{2 , 1}$ & $\mathbf{1 8 1}$ & $\mathbf{6 3 , 2}$ & $\mathbf{9 6}$ & $\mathbf{3 3 , 6}$ & $\mathbf{2 8 6}$ & $\mathbf{1 0 0 , 0}$ \\
\hline
\end{tabular}


banyak didapatkan konsultasi gangguan dengar pada anak setelah mencapai usia 2 tahun bahkan lebih. Keadaan tersebut mungkin karena kurangnya pengetahuan masyarakat khususnya orangtua akan tanda gangguan dengar pada anak serta kurang mengetahui bahwa gangguan dengar kongenital bila tidak ditangani secara dini akan mengganggu perkembangan berbicara dan berbahasa. Selain itu dapat juga disebabkan karena pengetahuan petugas kesehatan yang masih kurang. ${ }^{4}$

Subjek penelitian sebagian besar dari daerah perkotaan, hal ini mungkin karena pengetahuan dan keadaan ekonomi masyarakat perkotaan lebih baik, sehingga pemeriksaan BERA lebih terjangkau. Sebagai perujuk yang terbanyak adalah dokter spesialis THT dan dokter residen THT, mungkin disebabkan karena kebanyakan subjek langsung datang ke spesialis THT dan poli THT RSHS. Di samping itu mungkin juga subjek datang ke dokter umum atau ke spesialis anak, kemudian dirujuk ke spesialis THT atau Poli THT, tetapi pada penelitian ini tidak tercatat siapa yang merujuk ke spesialis THT dan poli THT tersebut. Penelitian Saim seperti dikutip Asad ${ }^{4}$ di Malaysia pada 122 anak dengan SNHL bilateral kongenital, urutan perujuk terbanyak adalah spesialis THT $(42,6 \%)$, spesialis anak $(32,8 \%)$, dokter umum $(8,2 \%)$, dan lain-lain $(5,2 \%)$.

Jika petugas kesehatan di berbagai unit pelayanan memahami dan ikut berperan dalam deteksi gangguan pendengaran kongenital pada anak, maka rujukan ke klinik Audiologi dapat datang dari berbagai sumber.

Pada penelitian ini didapatkan bahwa pada semua kelompok usia angka kejadian gangguan dengar sebagian besar adalah derajat berat dan sangat berat. Hal ini sesuai dengan kepustakaan bahwa derajat gangguan dengar kongenital sebagian besar adalah derajat berat dan sangat berat. Penelitian Saim seperti dikutip Asad ${ }^{4}$ di Malaysia mendapatkan hasil sebagai berikut: ringan 2,5\%, sedang $16,4 \%$, berat $16,4 \%$, dan sangat berat $64,7 \%$.

Gangguan dengar simetris lebih banyak dibandingkan dengan asimetris untuk semua derajat gangguan dengar. Hasil pemeriksaan ini sangat penting untuk menentukan telinga mana yang akan dipasang alat bantu mendengar. Pada gangguan dengar asimetris telinga yang dipasang alat bantu mendengar adalah telinga yang derajat pendengarannya lebih baik.

Tampak urutan 4 besar faktor risiko yang didapatkan adalah tidak dapat diidentifikasi, prematur/BBLR, asfiksia, dan hiperbilirubinemia, sedangkan penelitian Saim di Malaysia ditemukan urutan tidak dapat diidentifikasi, rubela, prematur, dan herediter. Hasil penelitian Asad, ${ }^{4}$ mendapatkan urutan empat besar sebagai berikut: tidak dapat diidentifikasi, prematur/BBLR, rubela, dan asfiksia.
Tindakan yang harus dilakukan untuk mencegah gangguan dengar tersebut adalah 1) perlu diadakan upaya tindakan pencegahan/preventif primerterhadap faktor risiko gangguan pendengaran kongenital dengan melakukan imunisasi, pemeliharaan higiene dan nutrisi yang baik, perbaikan praktik pelayanan persalinan, deteksi dan penanganan inkompatibiltas $\mathrm{Rh}$, serta penyuluhan kesehatan telinga/menghindari penggunaan obat ototoksik, 2) perlu peningkatan pengetahuan tenaga kesehatan, baik dokter umum maupun paramedis, dalam hal deteksi dini dan faktor serta rujukan anak yang dicurigai, dan 3) diadakan program penyuluhan pada masyarakat mengenai berbagai faktor risiko gangguan dengar dan pentingnya deteksi dini.

\section{Daftar Pustaka}

1. Kunst HPM, Marres H, Van Camp G, Cremes C. Non-syndromic autosomal dominant sensorineural hearing loss: a new field of research. Clin Otolaryngol. 1998;23:9-17.

2. Sataloff RT, Sataloff J. Hearing loss in children. Hearing loss. Edisi ke-3. New York: Marcel Dakker, Inc; 1993.

3. Corlson DL, Reeh HL. Pediatric audiology. Head and neck surgery-otolaryngology. Bailey. Edisi ke-2. Philadelphia: LippincottRaven; 1998.

4. Asad E. Aspek klinik dan sosiologik gangguan pendengaran sensorineural bilateral kongenital pada anak balita yang dideteksi dengan pemeriksaan BERA (Tesis). Bandung: Universitas Padjadjaran; 2003.

5. Djelantik BD. Progressive autosomal dominant hearing loss due to a genetic defect on chromosome 1 in families from West Java. An audiologic and genetic study (PhD thesis). Antwerp: Antwerp University, Belgium; 1996.

6. Abiratno SF. ABR pada tumor angulus serebelopontin laporan kasus. Konas Perhati VIII. Ujung Pandang, 1986.

7. Itano CY. Factors predictive of successful outcomer of deaf and hard of hearing children of hearing parents. USA: University of Colorado Website; 1998.

8. Bess FH, Humes LE. Screening auditory function. Audiology the fundamentals. Baltimore: William and Wilkins; 1990.

9. Davis A, Wood S. The efidenfiology of childhood hearing impairment: factors relevant to planning of services. 1992.

10. Finitzo-Hieber, T. Auditory brainstem response: It's place in infant audiological evaluations. Sem In Speech and Hear. 1982;3:76-86

11. Hall JW. Assesment of peripheral and central 
auditory function. Head and neck surgeryotolaryngology. Edisi ke-2. Philadelphia; Bailey BJ; 1998.

12. Maurer J. Otoacoustic emissions (OAEs)-SIPAC. American Academy of Otolaryngology-Head and Neck Surgery
Foundation, Inc; 1997.

13. Northen JL. Downs MP. Screening for hearing disorders: hearing and children. Edisi ke-4. Baltimore: Williams and Wilkins; 1991. 